\title{
CONTRIBUIÇÃO PARA UM INQUÉRITO LINGÜISTICO NO LITORAL DO PARANÁ
}

\author{
Serafina Traub Borges do Amaral \\ Licenciada em Letras Neolatinas pela \\ Universidade do Paraná
}

Em maio e em setembro de 1953 realizou-se, sob a competente e entusiástica direção do sempre lembrado professor Osvaldo Pinheiro dos Reis, uma excursão de pesquisa lingüística ao litoral do Estado, na qual os componentes ( 8 alunos de Filologia Românica) levavam tarefas claramente delimitadas para maior eficiência na colheita de dados. Era intenção do professor Pinheiro dos Reis, com o material recolhido e que lhe fôra por nós mesmos ofertado, escrever um trabalho sôbre 0 assunto. $O$ súbito e nunca suficientemente lamentado falecimento do prof. Pinheiro dos Reis, levou o Centro de Estudos Lingüísticos do Paraná a se interessar pelo assunto, tendo sido, porém, inúteis todos os esforços no sentido de localizar os originais dêsse trabalho.

O desejo de prestar uma homenagem ao meu caro professor, pioneiro da pesquisa dialetal no Paraná, e 0 apoio e incentivo que me foram dados pelos ilustres professôres Dr. Mansur Cuérios, da Faculdade de Filosofia, Ciências e Letras do Paraná, e Dr. Heinrich A. W. Bunse, da Faculdade de Filosofia, Ciências e Letras do Rio Crande do Sul, levam-me hoje a dar publicidade às anotações tomadas durante aquela pesquisa que, assim, não ficará inteiramente perdida, servindo, talvez de encorajamento a outros estudiosos do assunto.

\section{O LUGAR}

Rio dos Medeiros, município de Guaraqueçaba, está situado sôbre o braço direito do rio Medeiros, na margem ocidental da baía de Cuaraqueçaba, Paranaguá, Paraná, Brasil. 
Vilarejo que não merece sequer registro na carta da baía de Paranaguá, editada pelo Ministério da Marinha, tem cêrca de 20 casas - das quais 12 à margem do rio e as demais no interior. Tem aproximadamente 80 habitantes que se dedicam às ativida. des da lavoura e da pesca. como meio principal de subsistência $\mathrm{e}$ às indústrias caseiras da feitura de cestos, rêdes, farinha, cerâmica, como atividades suplementares. As culturas mais importantes são as do arroz e da mandioca, embora se plante ainda a batata doce.

As comunicações se fazem ùnicamente por via maritima, não havendo nenhuma espécie de viatura. Os caminhos que existem são poucos e maus, simples picadas, quase sempre alagadas, que mal dão passagem a uma pessoa, obrigando à tão conhecida formação em fila indiana.

\section{OS INFORMANTES}

Todos prestaram. com a maior boa vontade, tôdas as informações pedidas. São analfabetos, com exceção de dois rapazes que prestaram serviço militar e voltaram alfabetizados. O caráter físico mais notável é a ausência dos incisivos superiores n quase totalidade dos habitantes. São, na maior parte, mestiços. com acentuados traços indigenas.

Destaco "Senhorinha de Manuel Águeda" como principal informante. E' conhecida por "Si' ora ou Siuri(n)a di Mané Aguida" - nome de solteira - já que seu pai é muito mais conhecido que o marido. Analfabeta. Como caracteres psicológicos: atenta, cortês, extremamente hospitaleira; um pouco esquiva de início. comunicativa e até alegre, depois de quebrada a reserva do primeiro encontro.

\section{A LINNCUA}

\section{Observações fonéticas:}

O que primeiro nos chama a atenção em Rio dos Medeiros como aliás em quase todo o litoral do Estado do Paraná. dentrc da Baía de Paranaguá - onde primeiro notei o fenômeno peio menos, é a não pronúncia do som línguo-palatal j. Assim, pronunciam lórie por Jorge; ingrêia por igreja, etc. Outro fenömenos interessante é a desnasalaçāo constante: bánána, fándángo, 
minguánte, etc. A pronúncia dos rr chama a atenção pela acentuada diferença dos $\mathbf{r}$ do planalto. O $\mathbf{r}$ medeirano é um $\mathbf{r}$ líquido, paulista, bem diferente do $\mathbf{r}$ bem nítido, línguo-dental, do curitibano, por exemplo. Esse $\mathbf{r}$ peculiar dos medeiranos será representado neste trabalho por $r$ em negrito.

A articulação do I, bem nítida, quando aparece entre vogais; aparece meio confusa, ora como $\mathbf{r}$, ora como $\mathbf{i}$, quando vem antes de outra consoante: arquêre (alqueire), êis (ế'es), isto é, êles > êls > êis; cáine (carne). A articulação do s é peculiar, pois que é pronunciado $\mathbf{x}$ (de xarope) ou às vêzes com o som de $\mathbf{g} \mathrm{e} \mathbf{j}$ em espanho:: véxu (verso), Néxu (Nelson), cajca (casca), trêij (três). Represento por $\mathbf{x}$.

As consoantes $\mathbf{d}, \boldsymbol{t}, \boldsymbol{m}$ são bem nítidas: $\mathbf{d}$ articulado perfeitamente como fonema línguo-dental sonoro, e o t como surdo. Da mesma forma o $\mathbf{m}$ é nitidamente articulado.

O som ch é pronunciado tch ou tx: lántcha (lancha) rántcho (rancho), etc. $O$ que no português comum é ch, no medeireir., vale por tch (tx), embora eu o represente por ch.

O $\mathbf{i}$ e $\mathrm{O}$ u nasais são aqui representados por $\mathbf{n}$ entre parênteses depois dessas vogais; assim: $\mathbf{i}(\mathbf{n}), \mathbf{u}(\mathbf{n})$.

\section{Observaçōes morfológicas:}

Os verbos têm apenas duas formas diferenciadas: a da primeira pessoa e as restantes, tôdas iguais. Fica, p. ex., o presente do indicativo, conjugado assim: eu iógo, tu ióga, nóis ióga êis ióga.

No tratamento vemos que se usa a segunda pessoa do singular - tu, mecéis, sinhor (indiferentemente para o sexo masculino ou feminino - o que dá um sabor medieval à conversa "A sinhor num viu o fándángo?"), nhô - esta última forma usada na ausência da pessoa - "Tu díiz apra nhô Antónho..." mas na presença desse Sr. Antonio chamaram-no sinhor.

A concordância entre o substantivo e o adjetivo, quanto ao gênero sempre se faz de modo especial: o substantivo é feminino, mas o adjetivo se conserva sempre masculino: "Qui minina lindo!", "Um doença desse...,", "um guri", "um guría".

As formas duplicadas são muito comuns, principalmente entre as mulheres: "Têim tánta dô, tánta dô, tánta dô..." "A sinhôr põi sa in riba dêi êli férvi, férvi, férvi, férvi, faiz úm ispumarada i mórri". 
Expressões locais são ainda: "antis témpo" para significar antigamente; "matar taíi(n)a" (matar tainha) e "caçá pêxe"; o uso da palavra "tiúco" (tejuco) para significar barro ou mesmo areia molhada.

A respeito da construção da frase, veja na parte final.

Seguindo o "Estudo dos dialectos e falares portugueses" do Prof. Manuel de Paiva Boléo, da Faculdade de Letras de Coimbra, darei, a seguir, o vocabulário recolhido, referente à natureza, trabalhos agrícolas, animais domésticos — tarefa que me fôra designada nessa pesquisa.

\section{A NATUREZA, OS FENOMENOS ATMOSFÉRICOS, ASTROS, TEMPO.}

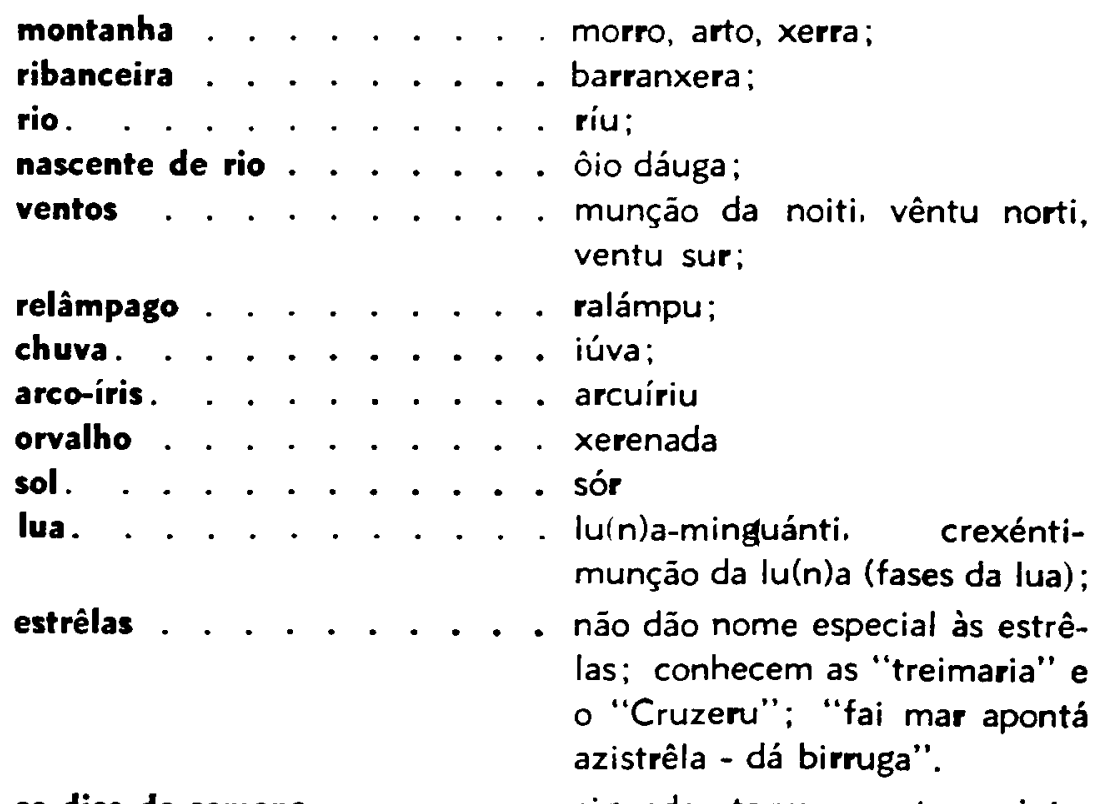

os dias da semana . . . . . . sigunda, terxa, quarta, quinta, sejta, sabo, dumingo.

os meses do ano . . . . . . . ianêro, feuerero, marxo, abri, maio, iunho, iulho, agojto, sitêmbo, oitubo, novembo, dijembo. 
manhã, meio-dia, tarde, noite . minhã, mêo-dia, tardi, nôiri; hoje, ontem, amanhã . . . . . ôie, ônti, ontônti, aminhã; as estações do ano . . . . . . nu témpu du quénti, nu témpu du fríu;

os numerais . . . . . . um, dôi, trêi, sêi, xincuenta. cuartôze, córenta i xincu, trinta $i$ xincu, sexenta $i$ trêi;

mil, milheiro . . . . . . . mí; miêru, cém mí réi; cento . . . . . . . . . . . xento; alqueire. . . . . . . arquêri (um sácu de dôi arqueri, um córenta quílo);

dúzia, quilo, litro . . . . . duza, quilo, litro.

uma porção . . . . . . u(n)a (u nasal + a) porxão.

muito (adv.) . . . . . . uma redada.

AS PLANTAS:

árvore . . . . . . . . . arvi;

jaboticaba . . . . . . . iabuticáua;

mastruço . . . . . . . . . mentruij

gomos da laranja . . . . bagu da laránia;

alecrim . . . . . . licrim (usado em defumação, quando nasce uma criança - 1:vra do mau olhado).

descascar (um fruto) . . . dicajcá.

cereais . . . . . . . míio, arrôi (marelão, bránco, mạ. relão vermêio, igapi( $n)$, matão bránco)

semente de laranja . . . . carôxo tangerina . . . . . . laránia mimósa

laranja . . . . . . laránia grándi

limão . . . . . . . . . . limão dôxi e ajedo

pimenta . . . . . . . pimenta preta e pimenta cumaí pinhão . . . . . . pi(n)ão (desconhecem a pinha; não há pinheiro no litoral).

mandioca . . . . . . mándióca (para fazer farinha); aipí (para comer cozido).

espiga de milho . . . . . . ispiga (a do arroz também é ispiga ou frô). 


cogumelos . . . . . . . . . . . chapéo di cóbra.
podar . . . . . . . . . . capá a árvi.
gomo de laranja . . . . . . . . . bago da laránia.
melancia . . . . . . . . . milánxía

Sendo a cultura do arroz a mais importante, procurei estudar melhor o assunto: O arroz (os "arrôi", "côiê us arrôi", "prantá us "arrôi") é plantado a cêrca de três quilómetros da margem do rio, em zona alagadiça, que deve abranger mais de cinco mil metros até o sopé de um morro, cuja encosta é plantada de mandicca (ráma). O plantio do arroz começa em junho ou julho e é coIhido em fins de abril ou principios de maio. $O$ trabalho é comum aos homens e às mulheres - a não ser que estas estejam de "famiia nova". Trabalham descalços, com água até o joelhc, enterrando as mudas no lôdo que formam o fundo do alagado. $\mathrm{Na}$ colheita apanham o "frô" ou "ispiga du arrôi" e empilham-na em casa, a um canto da sala. Como instrumentos agrícolas, usam a pá, a enxada, e ta'vez outros. A "frô" colhida é posta em sacos que mulheres e crianças carregam sôbre a cabeça, em sucessivas viagens, pelas trilhas que as freqüentes viagens traçam até à orla do rio.

Empilhado o arroz, e pronta a colheita de todos os plantadores. organizam-se "fándángos" - danças típicas de todo o litoral paranaense - que tomam o nome de "gámbá", um em cada casa em que há arroz a ser debulhado, pois a dança consta de um sapateado executado, descalços os participantes, sôbre o arroz espalhado no chão. $O$ atrito dos pés faz com que, ao fim da dança. após terem sido espalhadas sucessivas camadas de espigas, o arroz esteja completamente debu hado. - A explicação me foi dada assim: "U gámbá é u fándángu mêmu, dona, só qui é in ribá du arrôi seim sapatu neim tamáncu. . E' uma vêi in casa di cada um qui teim os arrôi." - Uma vez debulhado o arroz é vendido em Paranaguá a "cêim mi réi" o saco de "dôi arquêri" (aproximadamente $45 \mathrm{~kg}$.), e, com o resultado da venda, compram os artigos de que necessitam.

Além do arroz, plantam ainda mandioca (para feitura de farinha) e aipim (comestível), que têm o nome genérico de "ráma" - "aquêli artu ali é só ráma": "agóra tá nu tempu di prántá ráma". 
O café só é plantado ocasionalmente; as plantas que vi, por certo muito antigas, eram altíssimas, tornando a colheita uma verdadeira acrobacia; e, apresentando. no mesmo pé, bagos verdes, rosados, vermelhos e fiôres ao mesmo tempo. Secam-no em casa, torrando-o em uma "fríidera" (espécie de tigela rasa, de barro, de feitura doméstica) com algumas colheres de açúcar escuro e três ou quatro dentes de cravo da India "prá dá sabô". O café é sempre coado na hora de ser servido, do contrário, ficaria "amargôsu" ou "venenôsu".

Embora a mulher trabalhe a par do homem no serviço agricola, ela não se ocupa com as tarefas correlatas com a pesca. E' o homem quem tece as rêdes, os cabos e os tinge com a fervura do cipó "iacatiró". Em compensação nenhum homem se ocupa da cerâmica, tarefa feminina por excelência.

OS ANIMAIS:

animal . . . . . . . . alimá;

focinho . . . . . . . foci(n)u;

feminino de cachorro . . . . cachórra;

ovo, ovos . . . . . . . zóvu — "Oi qui um zóvo pra sinhor iantá" _ " "sinhor" no sentido de senhora - feminino (arcaico)

gema . . . . . . . . iêma

clara . . . . . . . . . . crara.

galinha, galo, frango . . . gali(n)a, galo, frángo.

cobra

Há poucas; só há uma que é venenosa; é a "corá", mas muito rara. Ouvi a um dos circunstantes: "Cóba simpênti".

os cães . . . . . . . . Há muitos. e assim designados: Avánti, Siguru, Tupi, Dragão. Livánti (veadêru di premera).

pesca Não se usa a palavra pesca, e sim "matá pêxe" ou "caçá pê$x e^{\prime \prime}$.

lagarto, lagartixa . . . . ialgato, lalgatixa. 
porco . . . . . . . . porco, pórca, curê (Para chamar usam: "curê. curê...")

chiqueiro . . . . . . . chiquero.

peixes

badejão. tubarão, cação. bagre. pescada, pescadi(n)a, jairé, raia, carãi(n)a, ôstra, camarão.

\section{Insetos:}

mosquito, mosca . . . . pernelôngo, mosca e mosca mordedêra. pulga, barata. piolhos, etc. . . bichu, bichu de cabeça, bichu de cáma. etc.

caça . . . . . . . . Não há armas de fogo; a caça é feita com armadilhas a que chamam "mundéo", com que caçam tatu, preá e até "viado", segundo um informante não muito digno de crédito (Moacyr Águeda). Não tive oportunidade de ver um mundéu, mas informaram-me que é mundéu de laço, embora isso não me esclareça a questão. $O$ "bodoque" ou "bedóque", de desenho especial, como um arco de flecha, com que atiram uma pedra a distâncias bem respeitáveis, tem a preferência dos meninos para a caça de passarinhos.

Verificamos que, com exceção de galinhas, cães, um único gato e dois porcos, nada há quanto a animais domésticos na maioria dos lares medeiranos. Os cães pertencem especificamente a cada família, mas o mesmo nāo se pode dizer das galinhas "criação" - que andam por tôda a parte e que pertencem mais ou menos a todos — "As mi(n)a criação tá tudo ispáiadu".

Passáros sabiá, bimtiví, tico-tico, bunitu-lindu, biguá (uma espécie de mergulhão), galça ou gaiça, e pintassírvi.

Abelha . . . . . . . abêia. O mel só é usado quando encontrado no mato. "A iênti a vi acha mer. cuándo é tempu di prántá ráma, nus mato". 


\section{A frase:}

Chamou-me a atenção ainda a construção da frase, por exemplo:

- Essa iênti senta na bêra dus capim... (referente aos espectadores de um jôgo de futebol - animadíssimo, aliás).

- Cum chúua tá muiadu u cámpu...

- Si u guvernu dasse di(n)ieru... (queixa contra a falta de escola no local - falta saneada mais tarde - Já em setembro, na segunda viagem que fizemos, havia. uma escola).

- U'a duença dêsse dêxa as pessoua fracu...

- Qui minina lindu...

- A sinhor qué iatá? - dirigindo-se a uma pessoa do sexc feminino.

- lórie, vêi(n)a tumá um górpi di café cá sua vó... (Tradução: Jorge, venha tomar um gole de café com sua avó...)

- A sióra vái pur ali, garra êssi cami(n)u tuda vida, dispois da derradêra casa, é lá...

- Mais cuma êli tá bunitu tudo di arvo... (Mas, como êle está bonito todo de branco... - Referência ao nenê que recebera de presente um enxoval todo branco).

— E' m'ermão, teim cincu fíu máchu, túdu moránu cuêle...

- Agora num si fái lôça di barro, pur causa dus arrôi (a co. lheita) issu é sirviçu pra quondo a ienti tá cus dêdu limpu (nãu tem o que fazer)...

Na primeira visita que fizemos, verifiquei que não havia nenhuma criança de menos de cinco ou seis anos presumiveis entre a farta população infantil local, admirada, perguntei se havia muito não nasciam nenês, e obtive a seguinte resposta:

Tiã muitu. mais a duença bateu aqui $i$ levou tudo a safra nova...

- E os seus não tiveram a doença? Que doença era?

- Deu a tossi cumprida aqui, qui levou tudu, os meu num tivéru, mais iscundi ê'is por baxo das fôia (frase figurada que 
significa - tomei tôdas as precauçōes, disfarcei-os para que a doença não os visse)...

Do que aqui ficou registrado, verificamos que a língua usada em Rio dos Medeiros merece mais profundo e acurado estudo, e o terá, certamente, pois que o assunto o exige.

O povo de Rio dos Medeiros é cavalheiresco e gentil, atento e hospitaleiro. Pudemos observar que a sua vivacidade de espirito não fica atrás da de qualquer brasileiro de cidade grande. que pode ser enganado, mas sabe que o está sendo, e só o permite por uma questão de, digamos, espírito esportivo. Senão, atentem para a expressão de um habitante do lugar ao ver desembarcar da lancha os componentes da caravana: "Ué, iênti, sirá qui têim inléição trá veij?" 